\title{
The risky lives of South Africa's children: Why so many die or are traumatised
}

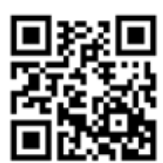

Of the $\mathbf{1 8 . 5}$ million children under the age of 18 in South Africa (SA), $8 \%$ have no fathers, $23 \%$ do not live with their biological parents, and $60 \%$ live in poverty - frightening figures that top local epidemiologists and clinicians agree help explain why the risk of a child dying here is ten times higher than in Europe.

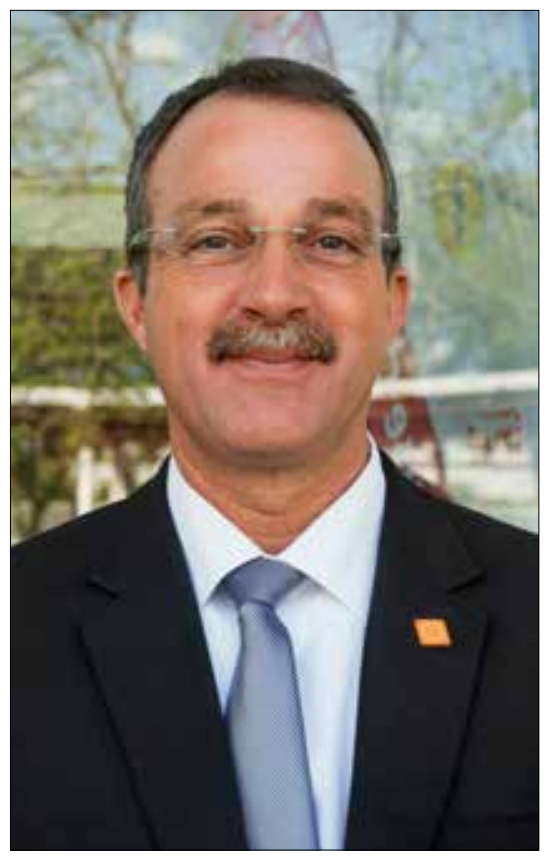

Prof. Sebastian van As.

These figures emerged with the release of the annual South African Child Gauge report by the Children's Institute at the University of Cape Town (UCT) in November 2014, and from an Izindaba interview with Prof. Sebastian van As, chief paediatric surgeon at Red Cross War Memorial Children's Hospital in Cape Town, the only dedicated children's hospital in the country. Since 1991, Red Cross Hospital has built up the world's single largest data base on child trauma. The experts at both institutions agree that poverty and the widespread, tragic absence of the most effective risk-mitigating factors possible one or both of a child's biological parents render the $8 \%$ of SA's children living in urban informal areas the most vulnerable as they roam danger-filled environments, many bordered by highways, train routes or bodies of water. HIV/AIDS in the pre-antiretroviral (ARV) era has left SA with one of the world's largest orphan populations ( $3 \%$ being double orphans and $8 \%$ having no father). According to Katharine Hall, project leader of the Child Poverty Programme at UCT's Children's Institute, a major contributor to the Child Gauge, the overall orphan count rose dramatically from the early 1990s, with the graph currently levelling off (an indicator of how dramatically the introduction of ARVs has impacted on mortality). Hall emphasised that household survey data continued to show that children who were not living with their biological parents were 'overwhelmingly in the care of other kin' - a legacy of migrant labour and urban housing shortages. This was 'not something that poor households can easily resolve. An aggravating risk factor is that even those children lucky enough to have working parents or guardians are often left unsupervised as their primary minders leave in the early hours to eke out a living, and return home in darkness.

Van As told Izindaba that a child younger than 6 years of age was insufficiently developed neurologically to properly assess the dangers around him or her, with the lack of sufficient child-minding facilities and crèches in the townships a major problem. He feels so strongly about this that he believes it should a criminal offence to allow a child to wander alone unsupervised: 'If you let a dog roam free without a licence, you can be fined - but there's no legal protection for kids.' Asked about the ten times greater risk of an SA child dying v. a European one, Van As said this came from a World Health Organization country-by-country child mortality comparison. Three years ago his own unit had compared the relative risk of a child ending up in a Cape Town hospital v. a child being admitted to Birmingham Hospital in the UK. The data showed that there was a 25 times greater chance locally.

\section{Ten times as many children die in accidents as are abused}

SA was 'anything but a child-centred society', and the media attention on violence against children disguised the 'true numbers', which showed that ten times as many children died from accidental injuries as were violated.
Just 5\% (or 500) of the 10000 children seen at Red Cross Hospital annually were physically or sexually abused. (According to Western Cape Health Department policy, Red Cross Hospital admits only children 13 years old and younger). Van As and his Red Cross team of two trauma and three orthopaedic consultants (backed by an average of 10 paediatric registrars) admit 3000 children annually, 1000 suffering from burns and 2000 from a mixture of other injuries, the biggest overall killer being motor vehicle accidents. He said that poverty also drove malnutrition, which impeded neurological development, further hampering less-privileged children from reaching their full potential. The country's violent past and the generational passing on of violent behaviour, aggravated by widespread poverty, meant that 'we are world champions at killing children', he observed. In the hour Izindaba spent interviewing him, Van As treated a child with 32 fractures (as a result of domestic violence between adults with the child being used as a 'shield', a common cause of severe trauma) and watched another die after the upper part of her torso had been kept alive for two days. Hit by a heavy-duty truck while walking on a township road, she had literally been torn in two.

\section{The experts at both institutions} agree that poverty and the widespread, tragic absence of the most effective riskmitigating factors possible - one or both of a child's biological parents - render the $8 \%$ of SA's children living in informal urban areas highly vulnerable as they roam danger-filled environments, many bordered by highways, train routes or bodies of water.

\section{Violence learnt and passed on}

The 2014 Child Gauge report, entitled Preventing Violence against Children: Breaking the Inter-generational Cycle, found that over half of SA's children frequently experience some 
form of violence from a very early age. This had long-term consequences that could be avoided by investing in prevention initiatives. While there was a paucity of systematic research on the extent and range of violent experiences, population-based prevalence studies showed that over half of children experience physical violence at the hand of a caregiver, teacher or relative. Incidents of sexual violence were under-reported - a 'disturbing reality' when considering that half of the 45230 'contact crimes' against children reported in the 2013/2014 crime statistics were sexual offences (an average of 62 cases per day). A two-province study found that one-third of participating children experienced emotional abuse. Emotional violence and neglect, and corporal and humiliating punishment of children, were 'common in the home', where abuse and neglect especially of young children could result in death. Physical punishment at schools was still 'pervasive' in spite of being banned for almost 20 years.

Shanaaz Mathews, director of the Children's Institute and lead editor of the 2014 Child Gauge report, said that these experiences hampered a child's development, learning ability, self-esteem and emotional security and had long-term consequences for employment prospects and life expectancy. Hervé Ludovic de Lys, UNICEF's SA representative, said that the current epidemic of violence undermines the fabric of society, affecting productivity, well-being and prosperity. 'The good news is that it is possible to see a dramatic reduction in violence against children in a relatively short time by implementing the right strategies, allocating enough resources and mobilising the highest political will', he added brightly. Mathews said that the impact of violence went beyond physical scars. Research showed that an intergenerational cycle of violence was created when children were exposed to violence in their early years, with these children more likely to become perpetrators or victims of violence when they were older because of neurological and psychological damage.

\section{Parenting and life- skills programmes essential}

Parenting programmes could play a major role in providing essential support to families ravaged by poverty, intimate partner violence and substance abuse, while lifeskills programmes for young people could help develop communication and conflict resolution skills to deal with peer pressure, substance abuse and social norms that promoted violence between young men and between them and their partners. Within the social development services there was currently too much focus on response services instead of prevention and early intervention measures. Lucy Jamieson of the Children's Institute said that nonprofit organisations, which delivered the bulk of services on behalf of government, were 'not fairly compensated', resulting in a funding crisis that was hampering services to children and families in need. Dena Lomofsky of the research consultancy Southern Hemisphere said that while multiple intersectoral committees had been set up to strengthen collaboration between government departments and civil society, each structure tended to focus on 'a specific issue with little collaboration between them to address children's needs holistically' This led to a fragmented response to a complex problem that required strong leadership from within government. Joan van Niekerk of Childline South Africa said that the National Department of Health could play a key role by identifying caregivers and children at risk and referring them to social services - but this was 'neglected in both policy and practice'.

\section{In the hour Izindaba spent interviewing him, Van As} treated a child with 32

fractures (as a result of

domestic violence between adults with the child being used as a 'shield', a common cause of severe trauma) and watched another die after the upper part of her torso had been kept alive for two days. Hit by a heavyduty truck while walking on a township road, she had literally been torn in two.

\section{Violence 'normalised' in SA}

The Child Gauge report states that due to the 'normalisation of violence' in SA's past, there was now a widespread tolerance of it that would require 'a great deal of work', including engendering an attitude that 'preventing violence is everybody's business'.
Red Cross Hospital is home to one of the world's oldest child-safety NGOs. Started in 1978 by its renowned former head of peadiatric surgery, Prof. Sid Cywes, when he noticed that he was doing more operations on children hurt in accidental injuries than on those suffering from all other diseases combined, Child Safe SA is aimed at promoting awareness through research, interventions (e.g. educating caretakers, crèche managers and teachers), and advocacy - based on hard data. A prefabricated 'home' on the hospital grounds highlights all the potential dangers in every room of the house, including things like dangling electric kettle cords (responsible for a disproportionate number of nearfatal burns in toddlers), containers with water, and age-specific posters on 'Living safely' and 'Travelling safely'. The NGO won a global award at the 2008 World Safety conference in Mexico.

\section{Gun law improvements -} $70 \%$ fewer child gunshot admissions

A manifestation of the violence referred to in the Child Gauge report, and a shining example of basic interventions, can be seen in how Child Safe SA tackled a virtual epidemic of child gunshot wounds in 2000. That year the hospital's trauma unit treated 50 children with firearmrelated injuries, mainly 'collateral injuries' resulting from adults intending to harm other adults (most children were hit by stray bullets) - a 'morbid' measurement of how many bullets were fired in Cape Flats communities, sparking an evidence-based campaign supporting the NGO 'GunFree South Africa'. A petition demanding stricter gun laws was delivered after a march on Parliament, resulting in a new firearm bill being adopted in 2002 that requires a gun-handling safety competency certificate, raises the minimum age requirement for possessing a firearm from 16 to 21, and declares 'gun-free zones' (e.g. places of worship, schools, hospitals). After these changes in the law, there was an 'astonishing' 70\% decrease in admissions of children with gunshot wounds to Red Cross Hospital. 'We cannot make it better, we have to go out there and prevent,' Van As stressed.

\section{Chris Bateman}

chrisb@hmpg.co.za

S Afr Med J 2015;105(3):170-171.

DOI:10.7196/SAMJ.9462 